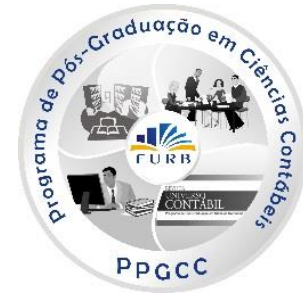

FRAUDES CONTÁBEIS E WHISTLEBLOWING: UMA PESQUISA EMPÍRICA SOBRE A INFLUÊNCIA DA PERCEPÇÃO CONTÁBIL DO DELATANTE'

\title{
ACCOUNTING FRAUD AND WHISTLEBLOWING: AN EMPIRICAL RESEARCH ON THE INFLUENCE OF THE DELATOR'S PERCEPTION OF ACCOUNTING
}

\section{FRAUDES CONTABLES Y WHISTLEBLOWING: UNA INVESTIGACIÓN EMPÍRICA SOBRE LA INFLUENCIA DE LA PERCEPCIÓN CONTABLE DEL DELATANTE}

Rossana Guerra de Sousa Mestre em Administração pela Universidade Federal da Paraíba Controladoria Geral do Estado da Paraíba Endereço: Rua Maria Rosa, 441, apto 1801. Bairro: Manaíra. CEP 58.038-460 - João Pessoa - PB E-mail: rossanagsousa@yahoo.com.br Telefone: (83) 3247-0977

\section{Adriana Fernandes de Vasconcelos} Mestre em Contabilidade Programa Multiinstitucional e Inter-regional de Pós-Graduação em Ciências Contábeis da UnB/UFPB/UFRN Professora da Universidade Federal de Pernambuco Endereço: Rua Manoel Cândido Leite, n. 1815. Bairro Tambauzinho. João Pessoa/PB - CEP: 58.042-320 E-mail: adrivasconcelos@hotmail.com Telefones: (83) 9342-6680

Gustavo Amorim Antunes Mestre em Finanças pela FUCAPE Departamento de Coordenação e Controle das Empresas Estatais - DEST/MP Endereço: Rua Ceará, № 18, ap. 05, Vila Planalto CEP 70.804-230 - Brasília - DF

E-mail: gaantunes@yahoo.com.br Telefone: (61) 2020-4578

José Dionísio Gomes da Silva Doutor em Contabilidade e Controladoria pela Universidade de São Paulo (USP) Professor Associado da Universidade Federal do Rio Grande do Norte (UFRN)

Endereço: Rua Aguinaldo Gurgel Junior, 2061 Cond. Villa da Colina - Casa 5 - Candelária CEP 59066-030 - Natal - RN

E-mail: dionisio@ufrnet.br Telefone: (84) 3215-3464

\footnotetext{
1 Artigo recebido em 23.10.2012. Revisado por pares em 23.04.2013. Reformulado em 16.09.2013. Recomendado para publicação em 20.09.2013 por Carlos Eduardo Facin Lavarda. Publicado em 30.09.2013. Organização responsável pelo periódico: FURB.
} 


\section{RESUMO}

A fraude corporativa é considerada um sério problema econômico e social, com efeitos adversos sobre uma ampla gama de partes interessadas e tem nas ações de denúncia interna (whistleblowing) seu principal fator de mitigação. Para um melhor entendimento das questões que levam a decisão de delação, o estudo examinou a interferência da percepção contábil do empregado sobre esta decisão. Foi conduzido um estudo exploratório com pesquisa de campo a partir da construção de um cenário hipotético, adaptado de Menk (2011) e da avaliação da percepção contábil, com questionário elaborado por Clikerman e Henning (2000). Os dados, analisados com análise fatorial e comparação de médias, apontam uma possível relação entre a melhor percepção contábil e a propensão a delação, demonstrando a necessidade da divulgação institucional e social da importância e do impacto das questões contábeis na busca pela redução dos casos de fraude contábil.

Palavras-chave: Contabilidade Comportamental. Whistleblowing.Fraude Contábil.

\section{ABSTRACT}

Corporative fraud is a serious economic and social problem, with adverse efects on various stakeholders and the most important factor to mitigate it is internal delation (whistleblowing). To adress this theme, we examine the influence of employee's accounting perception on complaint decision. This exploratory field research was implamented in three steps: a) an hipotetic fraud case was adapted from Menk (2011); b) the questionnaire developed by Clikerman e Henning (2000) was used to evaluate accounting perception; and c) the answers were crossed with factor analysis and mean comparison. The result suggests a possible relation between accounting perception and delation propensity, revealing that institutional education on accounting issues may contribute to reduce fraud cases.

Keywords: Behavior accounting. Accounting fraud. Delation propensity.

\section{RESUMEN}

El fraude corporativo es considerado un serio problema económico y social, con efectos adversos sobre una amplia gama de partes interesadas y tiene en las acciones de denuncia interna (whistleblowing) su principal factor de mitigación. Para una mejor comprensión de las cuestiones que toman la decisión de delación, el estudio examinó la interferencia de la percepción contable del empleado sobre esta decisión. Fue conducido un estudio exploratorio con investigación de campo a partir de la construcción de un escenario hipotético, adaptado de Menk (2011) y de la evaluación de la percepción contable, con cuestionario elaborado por Clikerman y Henning (2000). Los datos, analizados con análisis factorial y comparación de medias, señalan una posible relación entre la mejor percepción contable y la propensión a la delación, demostrando la necesidad de la divulgación institucional y social de la importancia y del impacto de las cuestiones contables en la búsqueda por la reducción de los casos de fraude contable.

Palabras clave: Contabilidad Comportamental. Whistleblowing. Fraude Contable.

\section{INTRODUÇÃO}

A fraude corporativa é considerada um sério problema econômico e social, com efeitos adversos sobre uma ampla gama de partes interessadas (stakeholdesrs). Do ponto de vista econômico, estima-se que as fraudes consomem, em média, 5\% da receita anual das empresas, equivalentes a U\$ 3,5 trilhões por ano, em todo o mundo, conforme pesquisa feita 
Rossana Guerra de Sousa - Adriana Fernandes de Vasconcelos - Gustavo Amorim Antunes - José Dionísio Gomes da Silva

pela The Association of Certifiede Fraud Examiners (ACFE, 2012). Os impactos sociais são sentidos especialmente por empregados, credores, pensionistas, além de clientes e fornecedores.

De acordo com a ACFE (2012), as fraudes corporativas podem ser classificadas em três categorias: roubo de ativos, corrupção e fraude contábil. O roubo de ativos e a corrupção tendem a ocorrer, inclusive simultaneamente, em $87 \%$ dos casos, mas respondem por uma pequena parcela das perdas financeiras das organizações (média de U\$120 mil anuais por empresa). Por outro lado, a fraude contábil representa $8 \%$ dos casos relatados na pesquisa, mas é responsável pelo maior montante de perdas financeiras (média de U\$ 1 milhão anual por empresa).

O estudo revela que $68 \%$ das perdas por fraude corporativa são atribuídas pelas organizações a fraudes contábeis e que o tempo gasto para sua descoberta é superior aos demais. A ACFE (2012) estima que as fraudes corporativas demandam 18 meses para serem descobertas, enquanto as fraudes contábeis podem levar até 24 meses.

Por esta conjunção de fatores, a fraude contábil gera efeitos negativos especialmente para o mercado de capitais (FENG et al, 2011), prejudicando a confiabilidade pública das informações e reduzindo a capitalização das empresas em U\$ 100 bilhões anuais. Segundo Karpoff, Lee e Martin (2008), as empresas perdem em média 38\% do seu valor de mercado quando desvios financeiros são divulgados.

Apesar de sua relevância, a fraude contábil permanece como um problema para as organizações e diversos fatores concorrem para aumentar este desafio: imprevisibilidade do evento, limitada experiência na detecção de fraudes pelos auditores (LOEBBECKE; EINING; WILLINGHAM, 1989) e tentativa de dissimulação do evento pelo fraudador.

Empregados têm sido apontados pela literatura acadêmica (NITSCH et al, 2005) como um fator crítico na detecção tempestiva das fraudes nas organizações. A ACFE (2012) estima que $43,3 \%$ das fraudes são descobertas por 'dicas' e denúncias, especialmente de empregados, contra apenas $14 \%$ via atuação da auditoria interna.

Apontado como peça fundamental na descoberta de fraudes, os empregados também são tidos como os principais responsáveis pela sua realização . De acordo com ACFE (2012), $80 \%$ das fraudes são efetuadas por empregados ou gerentes, especialmente da área contábil, setor responsável por mais de $20 \%$ dos casos de fraudes.

A primeira década do século XXI foi marcada por diversos desastres corporativos decorrentes de fraudes contábeis, inciados com o emblemático caso da Enron e chegando ao sistema financeiro com o Lehman Brothers. Esses escândalos, descobertos em grande parte por denúncias internas, mudaram as práticas das organizações e dos reguladores.

A reação mais conhecida a estes escândalos, na busca pela melhoria da qualidade das demonstrações financeiras, foi a publicação pelo governo americano da Sarbanes-Oxley Act (SOX, 2002), e da Dodd Frank Act (DFA, 2010). Entre outros, obrigou-se que as empresas listadas nos Estados Unidos criassem linha anônima e confidencial para os empregados denunciarem atos contábeis questionáveis e problemas de auditores (SOX, 301(4)).

Essa determinação segue a linha de atuação já defendida pela literatura acadêmica, como forma eficiente de descobrir comportamentos ilegais e questionáveis, a partir da participação dos empregados, sendo denominados de whistleblowing (McLAIN; KEENAN,1999; MICELI; NEAR, 1992).

Whistleblowing é o termo em inglês que denota a denúncia de práticas ilegais, imorais ou ilegítimas, direcionada por empregado para pessoas ou organizações que podem agir perante a fraude (NEAR; MICELI, 1985).

Nos últimos 20 anos, a pesquisa sobre denúncia interna tem sido conduzida por diversas disciplinas (KAPLAN; SCHULTZ, 2007) como destacado mecanismo de controle na prevenção e detecção de fraudes. Porém, trata-se de processo complexo, que envolve fatores 
pessoais e organizacionais, e tem sido abordado pela academia sob diversos contextos, buscando um entendimento mais profundo do tema.

Pesquisas dos antecedentes do denunciante (MESMER-MAGNUS; VISWESVARAN, 2005), diferenças demográficas (MICELI; NEAR, 1984) e relação com o lócus de controle (CHIU, 2003), tem buscado este entendimento, porém Hogan et al (2008) avaliam que mais estudos devem ser feitos sobre o tema.

No que diz respeito às fraudes contábeis, a divulgação das informações de natureza contábil pode ser considerada como ponto conflituoso entre gestores e usuários das demonstrações financeiras, já que estes últimos demandam pelo máximo de informação possível, enquanto os gestores buscam limitar a informação fornecida, o que pode ser explicado, de acordo com Watts e Zimmerman (1990), pelo fato dos seus desempenhos serem avaliados, em parte, pelos demonstrativos da empresa.

Os gestores podem encontrar um ambiente favorável para cometerem fraudes, considerando que possuem acesso a todas as informações, detém o poder na tomada de decisões nas empresas e podem ter motivos para alterar informações contábeis quando seu desempenho estiver ameaçado pelos resultados apresentados pela contabilidade. A partir das constatações das pesquisas da AFCE (2012), que apontam os empregados como responsáveis por denúncia das irregularidades, mas também como seus principais preparadores, o segmento da contabilidade como o local de maior ocorrência de fraudes, aliado ao impacto das fraudes em demonstrativos financeiros para o sistema econômico e social, bem como a utilização crescente, por força regulatória, de mecanismos de denúncia interna como ferramenta de controle na busca da prevenção e detecção de fraude, a pesquisa contábil deve voltar-se a este enfoque.

Nesse contexto, considerando que as fraudes contábeis são relevantes, que os empregados contribuem em suas descobertas e que características do indivíduo podem afetar sua propensão a denunciar, investiga-se a seguinte questão de pesquisa: empregados com melhor percepção contábil são mais propensos a delatar fraudes contábeis?

A partir da noção inicial que as diferentes percepções do empregado em relação papel da contabilidade estão relacionadas com a sua decisão de delatar fraudes contábeis, buscou-se examinar a hipótese que a percepção de menor importância e impacto das questões contábeis pelo empregado reduzem a possibilidade de denúncia interna de atos irregulares.

O estudo avalia o impacto de cinco fatores determinantes sobre as intenções de denúncia interna dos respondentes, utilizando-se de situação prática e clara de aplicação no mundo real. A motivação deste estudo é decorrente da importância das ações de denúncia interna (whistleblowing) nas operações do ambiente corporativo e busca o melhor entendimento dos fatores que levam a uma decisão individual de atuação em denúncias internas.

$\mathrm{Na}$ impossibilidade de investigar em situações reais o whistleblowing por parte dos empregados, as pesquisas têm utilizado a intenção comportamental de delatar como proxie operacional (CHIU, 2003). Nesse contexto, a Theory of Reasoned Action ou Teoria da Ação Racional tem sido a abordagem dominante para explicar a intenção comportamental como preditora de determinado comportamento no processo de tomada de decisão.

Para identificar a propensão a delatar, aplicou-se questionário contendo cenário hipotético de fraude, adaptado de Menk (2011), enquanto a percepção contábil foi avaliada quanto à cinco fatores específicos, a partir de instrumento elaborado por Clikerman e Henning (2000). Os dados foram coletados por meio de questionário eletrônico disponibilizado na internet, com a participação de 342 respondentes.

Os resultados de Menk (2011) sugerem que a propensão a delatar é maior nas pessoas que concordam com a divulgação ampla e responsável das informações, ou seja, empregados 
Rossana Guerra de Sousa - Adriana Fernandes de Vasconcelos - Gustavo Amorim Antunes - José Dionísio Gomes da Silva

com melhor percepção contábil são mais propensos a relatar as fraudes. Por outro lado, a propensão é menor nas pessoas que percebem os custos da divulgação contábil e justificam a manipulação das informações.

As evidências encontradas no estudo de Menk (2011) podem auxiliar no planejamento estratégico de ações de prevenção à fraude, através de programas específicos de conscientização quanto às questões contábeis e seus impactos para a organização, bem como demonstra a necessidade da divulgação institucional e social sobre a importância e impacto das questões contábeis na busca pela redução dos casos de fraude contábil.

Por fim, ressalta-se que este trabalho também contribui com a literatura sobre whistleblowing ao analisá-lo no Brasil, cujas particularidades culturais, apontadas por DaMatta (1996), podem afetar a propensão dos empregados a delatar.

O restante deste trabalho está dividido da seguinte forma: a seção 2 apresenta a fundamentação teórica relacionada a denúncias internas, a seção 3 contém os procedimentos metodológicos, a seção 4 contempla apresentação e análise dos resultados e a seção 5 apresenta as considerações finais.

\section{FUNDAMENTAÇÃO TEÓRICA}

Esta pesquisa está ampara em três eixos teóricos, relativos a: i) divergências entre gestor e usuário da informação contábil; ii) aspectos psicológicos da TRA (Theory of Reasoned Action); e iii) whistleblowing em contabilidade. Esses eixos são discutidos a seguir.

\subsection{Divergências entre Gestores e Usuários das Demonstrações Contábeis}

Historicamente, a divulgação de informação contábil tem sido uma grande batalha na história corporativa (ARANYA, 1978 apud CLIKEMAN; HENNING, 2000), na medida em que os investidores procuram por divulgações mais extensivas e os gestores buscam resistir a essa demanda, em virtude de suas performances serem monitoradas, em parte, através das demonstrações contábeis publicadas (WATTS; ZIMMERMAN, 1990).

Para Clikeman e Henning (2000) existem três questões que suscitam discordância entre os gestores e os usuários das demonstrações contábeis. A primeira delas diz respeito ao gerenciamento de resultados, entendido como a escolha de procedimentos contábeis para mover os números em direção a um patamar desejado. Assim, enquanto os gestores atingem suas metas, os usuários recebem informação enganosa sobre os resultados auferidos pela empresa.

A visão sobre a divulgação de informações confidenciais também é ponto conflituoso entre gestores e usuários. Enquanto estes acreditam que toda informação considerada relevante para suas decisões de investimentos devem ser divulgadas, os gestores argúem que uma extensa divulgação pode ajudar as empresas concorrentes.

O terceiro ponto diz respeito aos custos e benefícios da divulgação destas informações. $\mathrm{Na}$ visão dos gestores, o custo de prover as informações requeridas pelos usuários é excessivo, não superando os potenciais benefícios que pode trazer, enquanto na visão dos usuários os benefícios do disclosure superam estes custos.

Essas diferenças de opiniões, bem como a independência dos gestores frente à tomada de decisão, e o livre acesso as informações da empresa, tem gerado oportunidades para a ocorrência de fraudes, as quais muitas vezes só são descobertas em estágio avançado de execução. Para Lipman (2012), esses desastres são resultados de uma estrutura de governança corporativa falha, em particular no estabelecimento de procedimentos robustos de denúncias, e salienta que existem sete problemas principais nos atuais sistemas de denúncias adotados pelas empresas: 
- A alta administração tolera, mas não encoraja a denúncia, particularmente de executivos;

- Não há nenhuma recompensa ou reconhecimento para denúncias legítimas;

- Falhas de comunicação na denúncia anônima prejudicam as investigações;

- Os sistemas de denúncia interna não garantem o anonimato;

- A divulgação dos sistemas de denúncia não é satisfatória;

- Os membros do comitê de auditoria não são vistos como independentes por informantes e não têm conhecimentos forenses;

- A motivação e personalidades dos denunciantes afetam as investigações.

Assim, para que o sistema de denúncias seja efetivamente útil, é preciso encontrar maneiras de corrigir os problemas acima mencionados, fazendo com que as perdas ocorridas a partir de fraudes nas empresas possam ser gradativamente eliminadas, garantindo aos stakeholders a proteção de seus investimentos.

Este trabalho se relaciona com a última dificuldade apontada acima, pois avalia se o comportamento do empregado afeta sua propensão a delatar uma fraude.

\subsection{Aspectos Psicológicos da TRA (Theory of Reasoned Action)}

Existem, no âmbito da psicologia, alguns modelos teóricos denominados de modelos de intenções comportamentais, os quais "focalizam essa variável que antecede imediatamente o comportamento real e, por isso, provavelmente, tem alto potencial para prognosticá-lo" (LACERDA, 2007). Dentre esses modelos, a Theory of Reasoned Action ou Teoria da Ação Racional, também conhecida como Teoria da Ação Fundamentada, tem sido considerada como a abordagem dominante.

Esta teoria é uma corrente derivada da psicologia social, que estuda a intenção comportamental, abrangendo aspectos como previsão de atitude e comportamento. Ela foi concebida por Icek Ajzen e Martin Fishbein, em 1980, e tem sido utilizada em diversas áreas de conhecimento (psicologia, administração, enfermagem, nutrição, dentre outras) para entender o comportamento dos indivíduos frente à tomada de decisões. (GAMBAL, 1990; SABLE et al., 2006; LACERDA, 2007)

Para Ajzen e Fishbein (1980) a teoria tem como objetivos predizer e entender o comportamento do indivíduo. No que diz respeito à predição, é necessário inicialmente identificar e mensurar um comportamento de interesse e estando este definido, torna-se possível entender o que o determinou.

Para a teoria, o que irá determinar o comportamento de uma pessoa é a intenção que ela tem em executá-lo ou não. No entanto, os autores salientam que nem sempre existe uma relação perfeita entre a intenção e comportamento em si, ou seja, uma pessoa pode ter determinada intenção e não realizar o comportamento de acordo com a mesma, mas de maneira geral, as pessoas normalmente agirão de acordo com sua intenção (AJZEN E FISHBEIN, 1980).

Ajzen e Madden (1986) explicam que a teoria é fundamentada em dois conceitos. O primeiro é o de atitude para com o comportamento (attitude toward the behavior), e refere-se ao grau que uma pessoa é favorável ou desfavorável com relação ao comportamento em questão; a segunda é o de norma subjetiva (subject norm), que se refere à pressão social percebida para realizar ou não realizar o comportamento. Nesse sentido, as pessoas ponderam esses dois componentes, de acordo com a importância que atribuem para cada um, e os mesmos são assumidos para determinar a intenção comportamental.

Gambal (1990) explica que a TRA é utilizada para avaliar as intenções das pessoas para executar um comportamento específico. Isso ocorre com o exame das crenças sobre as 
Rossana Guerra de Sousa - Adriana Fernandes de Vasconcelos - Gustavo Amorim Antunes - José Dionísio Gomes da Silva

consequiências de realizar o comportamento e as percepções do apoio social que seria recebido no caso da ação ser executada, sugerindo que o melhor preditor do comportamento é a intenção de realizar o comportamento em questão.

Assim, o que TRA propõe se encaixa no fundamento psicológico deste trabalho, pois a intenção em denunciar fraude contábil mostra que a escolha dos indivíduos, a partir do seu exame sobre o caso em questão, faria com que tomassem a atitude de reportar ou não a fraude, no caso de uma real situação onde houvesse possibilidade de denúncia.

\subsection{Whistleblowing em Contabilidade}

O whistleblowing tem recebido grande atenção da literatura de negócios nos anos recentes, em função dos escândalos financeiros ocorridos na década de 2000 e o crescente interesse na ética e moralidade nas organizações (AVAKIAN; ROBERTS, 2011). Este termo, na visão de Near e Miceli (1985), é "a divulgação, por membros da organização (passados ou atuais), de práticas ilegais, imorais ou ilegítimas sob o controle de seus empregados, para pessoas ou organizações capazes de tomar ações efetivas", podendo ocorrer internamente ou externamente, no entanto, pesquisas indicam que a maioria dos denunciantes primeiro revela suas descobertas internamente antes de denunciá-los ao público (MICELI; NEAR, 2002).

A promulgação da SOX (2002), em sua seção 301 (4), trouxe a exigência de que o comitê de auditoria defina procedimentos para o estabelecimento de métodos de comunicação, confidencial e anônimo, para queixas relacionadas à contabilidade e auditoria. Dessa forma, a cultura da denúncia tornou-se largamente discutida, e para Elias (2008), a exigência de canais de comunicação de fraudes representou uma grande mudança na profissão contábil, que sempre valorizou a confidencialidade.

O DFA (2010), por sua vez, prevê uma potencial recompensa financeira para a pessoa que denunciar, desde que a informação fornecida seja dada de forma voluntária, o indivíduo seja o primeiro a relatar o problema e a informação leve a sanções monetárias superiores a U\$ 1,0 milhão. A aprovação da lei parte do pressuposto de que essa característica de recompensa financeira possa alterar as intenções de comunicação de muitas pessoas.

A respeito do whistleblowing, Elias (2008) salienta tratar-se de um processo complexo que envolve fatores pessoais e organizacionais, com conseqüências nas empresas, que merecem ser discutidas e entendidas, para um correto dimensionamento dos procedimentos adotados nos sistemas de denúncia interna nas empresas.

Menk (2011) afirma que muitos funcionários relutam em se envolver em denúncias de irregularidades em atividades, mesmo existindo proteção legal para a denúncia. Isso ocorre pois historicamente, os delatores têm recebido um tratamento de retaliação da empresa e de seus funcionários. Como conseqüências da denúncia, observam-se a rescisão docontrato, o rebaixamento do status e da remuneração, a dificuldade para avançar na carreira e o isolamento do denunciante.

Miceli e Near (1994) comentam que as organizações retaliam denunciantes a fim de evitar um conhecimento público da queixa, desacreditar o denunciante e desencorajar outros denunciantes potenciais. Essa retaliação pode ser imposta pelos gerentes de níveis mais baixos, com ou sem o conhecimento dos executivos das empresas.

Menk (2011) observa que alguns fatores impactam a decisão individual de relatar um problema encontrado, dentre eles, a ideia de que a denúncia é um comportamento que fornece benefício para a empresa e deve ser incentivada pelos gestores. Outro fator diz respeito à importância ou gravidade do problema ser um preditor na intenção de denunciar, assim quanto maior materialidade da fraude, mais provável levar um empregado a efetuar a denúncia.

Ainda como fatores impactantes na decisão, encontram-se o nível de comprometimento com o trabalho, que tende a aumentar a probabilidade de relato; bem como 
a situação ou forma dos comportamentos inaceitáveis. Assim, incidentes de assédio sexual, má gestão, ou ações ilegais são mais prováveis de serem relatados que casos de roubo ou preocupações de segurança. Observa-se ainda que fatores como religiosidade, ideologia ética do indivíduo e a possibilidade de uma mudança desejada podem ensejar a denúncia por parte dos empregados.

Esta pesquisa se insere nesse contexto, ao investigar se a percepção contábil do indivíduo afeta sua propensão a delatar fraude.

\section{PROCEDIMENTOS METODOLÓGICOS}

\subsection{Visão Global}

Para avaliar se a percepção contábil do indivíduo afeta sua propensão a delatar fraudes, foi conduzida uma pesquisa de campo onde os respondentes foram apresentados a uma situação hipotética de fraude.

O grupo de respondentes constitui-se de profissionais e estudantes de Contabilidade, e a amostra pode ser considerada aleatória. $\mathrm{O}$ instrumento de pesquisa foi disponibilizado através de coletor eletrônico e divulgado através da rede de relacionamentos dos autores, e obteve 342 respostas. Os perfis dos respondentes encontra-se detalhado na a Tabela 1. da área contábil

O processo de coleta de dados foi estruturado inicialmente solicitando posicionamento sobre a possibilidade de denunciar o caso relatado e, em seguinda, em tela diferente,que avaliassem 11 assertivas sobre contabilidade, utilizando-se, em todos os casos, escala Linkert de sete níveis.

Posteriormente, utilizando-se de Análise Fatorial, as assertivas foram condensadas em cinco fatores de análise, seguindo a metodologia proposta por Clikeman e Henning (2000). Com isso, foi possível apurar os valores médios de cada fator e comparar as respostas dos grupos com maior e menor propensão a delatar.

Adicionalmente, informações demográficas quanto ao sexo, idade e situação profissional foram incluidas no estudo para traçar o perfil dos respondentes. As variáveis de análise foram determinadas pela questão de pesquisa e definidas como a seguir:

A) Propensão a delatar - referente à decisão de denunciar ou não a fraude, medida em escala métrica discreta com variação de 1 a 6 , sendo 1 designado como certamente não comunicaria e 6 como comunicaria com certeza. $\mathrm{O}$ valor 7 foi utilizado para os casos em que o indivíduo não se sentia responsável pelo assunto.

B) Percepção contábil - referente aos cinco fatores construídos a partir das respostas às 11 assertivas de Clikeman e Henning (2000). Esses fatores espelharam conceitos relativos à deturpação, custo-benefício, divulgação, responsabilidade e transparência. Vale destacar que o questionário de Clikeman e Henning (2000) é citado na literatura como um instrumento adequado para avaliar a percepção contábil dos indivíduos (ELIAS, 2008).

\subsection{Questionário e Procedimentos Gerais}

O instrumento de coleta foi formado de três partes: i) coleta de dados demográficos; ii) exposição à situação de decisão, a partir do cenário de fraude adaptado de Menk (2011); e iii) apresentação das 11 assertivas elaboradas por Clikeman e Henning (2000).

Para reduzir a possibilidade do respondente não compreender que o cenário proposto contém fraude, foi inserida esta indicação expressa ao longo do questionário (apresentação e título) e na questão central. O possível efeito da magnitude da fraude na decisão denunciá-la foi controlado com a indicação expressa de que o fato é de alto impacto. 
Rossana Guerra de Sousa - Adriana Fernandes de Vasconcelos - Gustavo Amorim Antunes - José Dionísio Gomes da Silva

A aplicação deu-se com a utilização de coletor de internet e os respondentes foram contactados via rede de relacionamento dos pesquisadores.

A escala Linkert foi utilizada em ambos os casos com sete níveis. Para captar a propensão a delatar, os valores variaram de 1 (não comunicaria) a 6 (comunicaria com certeza), sendo que a opção 7 indicava "não tenho responsabilidade sobre isto". Para mensurar da percepção contábil, a escala utilizada variou de 1 (discordo totalmente) a 7 (concordo totalmente).

Os dados coletados foram segmentados em grupos de análise utilizando-se da indicação da possibilidade de denúncia atribuída na escala Linkert. Os grupos formados foram:

- $\quad$ G1 - Delação (respostas de 4 a 6) e;

- G2 - Não delação (resposta de 1 a 3).

A opção $n^{\circ} 7$ (não sou responsável sobre isto) foi desconsiderada no agrupamento (G3), pois apresentou baixa resposta e ausência de um padrão definido.

\subsection{Análise Fatorial}

O objetivo da utilização da análise fatorial foi condensar as informações contidas nas 11 assertivas em um conjunto menor de dimensões relevantes (fatores comuns), que possibilitasse uma melhor compreensão da percepção contábil dos respondentes. A opção pela técnica multivariada para selecionar fatores relevantes para avaliar a percepção dos respondentes minimiza o julgamento do pesquisador ao agrupar as respostas e reduz a possibilidade de inclusão de variáveis inadequadas no estudo.

A análise fatorial conduzida teve caráter exploratório do tipo $\mathrm{R}$, que calculou os dados de entrada a partir de uma matriz de correlação entre as variáveis métricas, tomadas como as 11 assertivas fornecidas.

As suposições iniciais para aplicação do modelo (HAIR et al, 2009), especificamente quanto à homogeneidade da amostra é suprida pelo próprio objeto comum de análise. Quanto às medidas de intercorrelação, foram utilizadas a matriz de correlação e anti-imagem, sendo consideradas correlações parciais elevadas àquelas superiores a 0,5 e o teste de esfericidade de Bartllet, com significância estatística de que a matriz de correlação tem estatísticas significantes pelo menos entre algumas variáveis, para valor $p<0,05$. Os testes foram conduzidos de forma sequenciada, iniciando com a utilização de todas as variáveis, eliminando-as a partir da matriz de anti-imagem até a obtenção de valores de correlação melhores possíveis.

O método de extração de fatores utilizado foi o da Análise de Componentes Principais, pois segundo Hair et al (2009), este é o mais adequado quando se pretende reduzir dados. Com a extração inicial dos fatores não-rotacionados, e utilizando o critério de autovalores ou raiz latente, foram definidos como significantes os fatores com autovalores maiores que 1 . Para obtenção de fatores com maiores potenciais explicativos e teoricamente mais significativos, segundo indicação do autor, o método de rotação ortogonal VARIMAX de fatores foi empregado. A avaliação das cargas funcionais não indicou necessidade de reespecificar o modelo.

\subsection{Análise dos Dados}

A amostra da pesquisa foi composta de 342 respondentes, distribuídos nos três grupos, sendo, ao final, 274 dados válidos, configurando-se 19,8\% de dados perdidos, em decorrência de respostas incompletas. Os grupos tiveram distribuição de respondentes de G1: 227 (82,85\%), G2: $37(13,5 \%)$ e G3: 9 (3,28\%). A distribuição demográfica entre os grupos não 
FRAUDES CONTÁBEIS E WHISTLEBLOWING: UMA PESQUISA EMPÍRICA SOBRE A INFLUÊNCIA DA PERCEPÇÃO CONTÁBIL DO DELATANTE

apresentou diferenciações significativas que fossem relevantes para o estudo e assim não são reportadas. A Tabela 1 evidencia os dados da amostra e o perfil dos respondentes.

Tabela 1- Informações sobre amostra e perfil dos respondentes

\begin{tabular}{|c|c|c|c|c|}
\hline & Total & G1 & G2 & G3 \\
\hline \multicolumn{5}{|c|}{ Painel A: Informações da Amostra } \\
\hline Amostra Inicial & 342 & & & \\
\hline Dados Perdidos & 68 & & & \\
\hline \multirow[t]{2}{*}{ Dados Analisados } & 274 & 227 & 37 & 09 \\
\hline & $(100 \%)$ & $(83 \%)$ & $(14 \%)$ & $(3 \%)$ \\
\hline \multicolumn{5}{|c|}{ Painel B: Perfil dos Respondentes } \\
\hline Estudante & $25,6 \%$ & & & \\
\hline Profissional em Exercício & $38,4 \%$ & & & \\
\hline Profissional e Estudante & $36,0 \%$ & & & \\
\hline Média de Atuação Profissional & 8,2 anos & 8,7 anos & 5,7 anos & 5,3 anos \\
\hline Idade & 31,1 anos & 31,7 anos & 28,7 anos & 26,1 anos \\
\hline
\end{tabular}

Fonte: Elaboração Própria

Seguindo procedimento de Clikeman e Henning (2000), aplicou-se análise fatorial às respostas sobre percepção contábil. Esse método identificou que as 11 assertivas podiam ser agrupadas em 05 fatores, que explicam $62 \%$ da variância das variáveis. O estudo original contou com a participação de 141 respondentes e identificou 04 fatores que explicavam $78 \%$ da variância.

A matriz de anti-imagem mostrou para esta composição de valores de correlações parciais superiores a 0,6 e o teste de esfericidade de Bartlett $\left(\chi^{2}{ }_{55}=249,28 ; p=0,000\right)$, indicando adequação da análise fatorial. A medida de adequacidade da amostra de KaiserMeyer-Olkin (KMO) apontou valores de 0,636, denotando a adequação da amostra para análise fatorial.

A Tabela 2 demonstra a classificação das assertivas sobre percepção contábil de acordo com os cinco fatores definidos pela análise fatorial. Foi mantida a nomenclatura utilizada por Clikeman e Henning (2000) para os quatro fatores comuns e atribuiu-se o rótulo de transparência para o quinto fator apresentado neste estudo.

Tabela 2: Fatores de percepção contábil

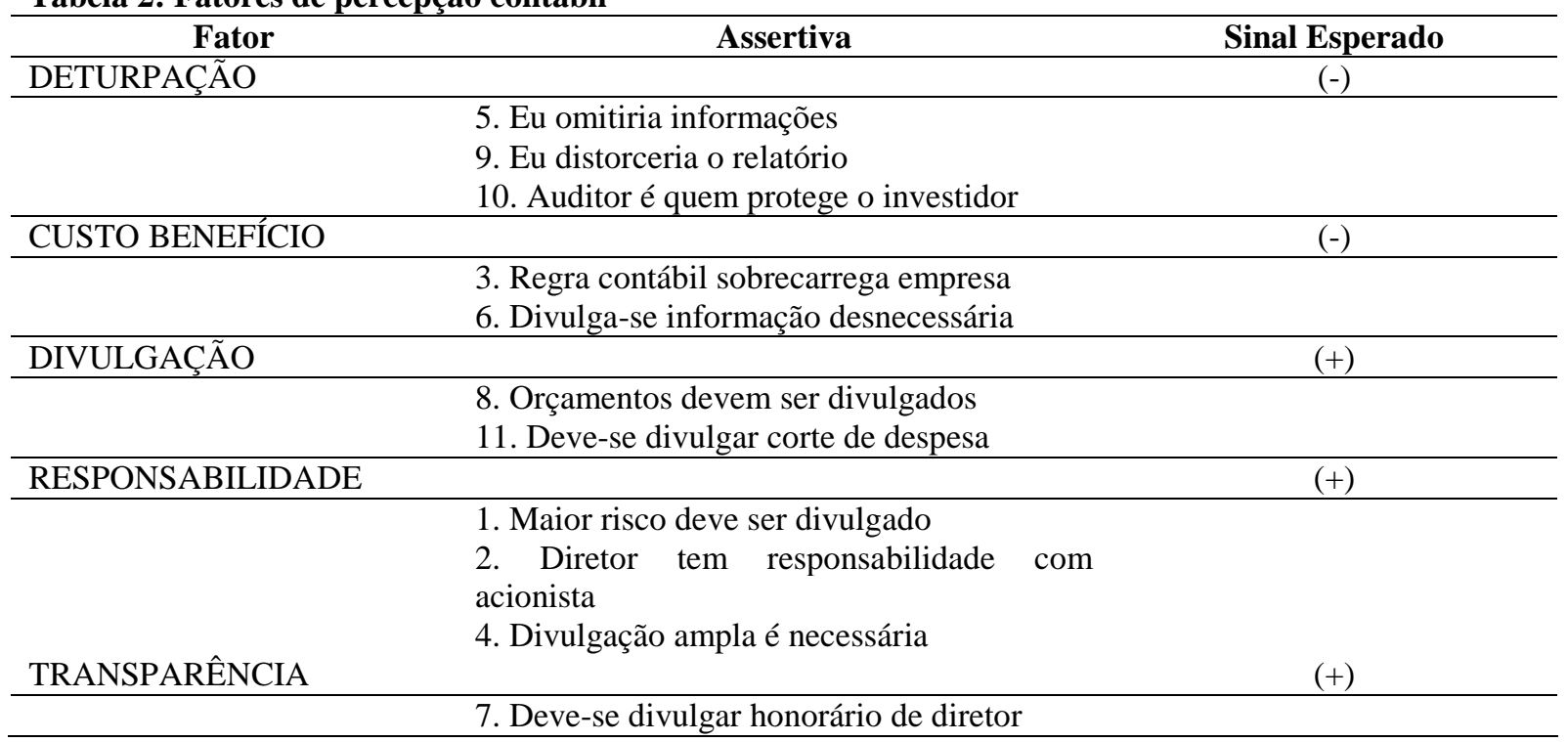

Fonte: Elaboração Própria.

Nota: (-) valor esperado quanto menor melhor na escala de 1-6; (+) valor esperado quanto maior melhor na escala de 1-6. 
Rossana Guerra de Sousa - Adriana Fernandes de Vasconcelos - Gustavo Amorim Antunes - José Dionísio Gomes da Silva

Para definir o valor dos cinco fatores apresentados acima, calculou-se a média dos valores atribuídos a cada assertiva que os compõem, conforme Clikeman e Henning (2000).

Seria recomendável aplicar testes estatísticos para verificar se as médias observadas são significantemente diferentes entre os grupos. Porém, a escala Linkert não gera dados com distribuição normal e não permite uso do tradicional teste $t$. Por outro lado, os testes nãoparamétricos ficaram prejudicados pela discrepância no número de respondentes de cada grupo (227 e 37).

Assim, houve comparação numérica simples e todos os resultados apontam para a mesma direção: maior percepção contábil afeta positivamente a propensão a delatar. Ademais, simulação do teste $t$ indica que a diferença entre as médias é estatisticamente significante.

\section{APRESENTAÇÃO E ANÁLISE DOS RESULTADOS}

Segundo Ajzen e Fishbein (1980), as pessoas normalmente agirão de acordo com sua intenção, mesmo não se observando uma relação perfeita. A Tabela 1 demonstra que a maioria absoluta dos respondentes (83\%) indica uma alta propensão a delatar a fraude contábil, o que implica, segundo a TRA, em um cenário favorável para as empresas na utilização do whistleblowing como instrumento para redução da ocorrência ou prevalência da fraude contábil nas organizações. O alto índice de propensão a delatar pode ser decorrente do crescente interesse pela ética e moralidade nas organizações, como relatado por Avakian e Roberts (2011).

Os respondentes que apresentam maior propensão à delação, como visto na Tabela 1, tem uma experiência profissional e idade maior que aqueles que indicam não delação como opção. Esta evidência é coerente com as afirmações de Menk (2011) que aponta como fatores impactantes na decisão de delação o nível de comprometimento com o trabalho, que pode ser alcançado com o amadurecimento profissional e pessoal.

Menk (2011) apresenta a ocorrência histórica de um tratamento de retaliação da empresa e dos outros funcionários como outro fator que pode, adicionalmente, explicar esta diferença na propensão a delatar, levando a relutância dos mais jovens e em início de carreira em realizar a delação, na busca da preservação da relação de emprego para o avanço na carreira.

A Tabela 3 apresenta os principais resultados da pesquisa, indicando que o grupo mais propenso à delação (G1) apresenta para os fatores Deturpação e Custo Benefício uma média menor, indicando menor concordância com a omissão de informações, distorção de relatórios, responsabilidade de auditores na proteção de investidores, sobrecarga de regras contábeis e a existência de divulgação contábil desnecessária.

Este mesmo grupo (G1) apresenta média maior para os fatores Divulgação e Responsabilidade, o que indica maior concordância com as divulgações de orçamentos, cortes de despesa, existência de maiores riscos, responsabilidade da direção com os interesses dos acionistas e divulgação ampla.

A análise em conjunto dos grupos (G1) e (G2) sugere que indivíduos com uma melhor percepção contábil tendem a apresentar maior propensão a delatar.

A percepção contábil relacionada à Transparência apresenta resultado inconsistente com o esperado, sendo maior a concordância com a divulgação dos honorários de diretoria no grupo que apresenta menor propensão a delação (G2). 
FRAUDES CONTÁBEIS E WHISTLEBLOWING: UMA PESQUISA EMPÍRICA SOBRE A INFLUÊNCIA DA PERCEPÇÃO CONTÁBIL DO DELATANTE

Tabela 3 - Percepção dos fatores contábeis e propensão a denúncia de fraude

\begin{tabular}{lccc}
\hline Fatores & Sinal & $\begin{array}{c}\text { G1 } \\
\text { Média } \\
\text { (desvio padrão) }\end{array}$ & $\begin{array}{c}\text { G2 } \\
\text { Média } \\
\text { (desvio padrão) }\end{array}$ \\
\hline DETURPAÇÃO & & 2,41 & 2,91 \\
& $(-)$ & $(1,39)$ & $(1,52)$ \\
CUSTO BENEFÍCIO & $(-)$ & 3,96 & 4,23 \\
& & $(1,70)$ & $(1,61)$ \\
DIVULGAÇÃO & $(+)$ & 5,28 & 5,12 \\
& & $(1,54)$ & $(1,23)$ \\
RESPONSABILIDADE & $(+)$ & 5,26 & 5,06 \\
& & $(1,20)$ & $(1,23)$ \\
TRANSPARÊNCIA & $(+)$ & 3,34 & 3,49 \\
& & $(2,80)$ & $(2,46)$ \\
\hline
\end{tabular}

Fonte: Elaboração Própria.

Esta aparente distorção pode ser explicada pela ainda controversa questão relacionada com a divulgação de remuneração de executivos no Brasil, que suscita questões judiciais como as relacionadas à apresentação do Formulário de Referência da Comissão de Valores Mobiliários (CVM), que torna pública a remuneração média de administradores. A característica especial deste fator para o cenário brasileiro pode ser observada desde a construção dos fatores relacionados à questão, que gerou um grupo específico, fato não observado no estudo original de Clikeman e Henning (2000).

\section{CONSIDERAÇÕES FINAIS}

As fraudes contábeis e seus conseqüentes impactos negativos na sociedade têm levado organizações, governos e academia a estudar meios de minimizar a probabilidade de sua ocorrência e aumentar a possibilidade de sua identificação oportuna.

Os empregados das organizações são apontados, ambiguamente, como os principais responsáveis pelas fraudes contábeis e como os instrumentos centrais na sua detecção. Políticas regulatórias, como a SOX (2002) e DFA (2010), e instrumentos gerenciais como os canais internos de denúncias (whistleblowing) têm se focado na busca de proteção social e particularmente dos interesses dos stakeholders.

Alinhado a estas preocupações no crescente mercado empresarial brasileiro, este trabalho busca contribuir com a literatura sobre o whistleblowing ao analisá-lo no Brasil, cujas particularidades culturais apontadas por DaMatta (1986) podem afetar a propensão a delatar do empregado e a possível eficiência deste instrumento.

O objetivo central deste estudo exploratório foi avaliar se a percepção contábil do empregado afeta sua propensão a delatar, a partir da utilização de um cenário hipotético de fraude, adaptato de Menk(2011) e de questionário elaborado por Clikerman e Henning (2000). O estudo limita-se ao cenário brasileiro e os resulados não podem ser generalizados.

Os resultados sugerem que a propensão a delatar é maior nos respondentes que concordam com uma divulgação ampla e responsável das informações e menor nos que justificam a manipulação das informações.

Aponta ainda, consistente com a literatura, uma grande propensão a delatar entre os respondentes, fato decorrente da busca por ética e moralidade nas organizações. Ainda em linha com a literatura, os respondentes com média de idade mais alta e maior tempo de atuação profissional apontam maior propensão a delatar que os mais jovens e em início de carreira. 
Rossana Guerra de Sousa - Adriana Fernandes de Vasconcelos - Gustavo Amorim Antunes - José Dionísio Gomes da Silva

O estudo evidencia a particularidade do cenário brasileiro em relação à divulgação de informações sobre remuneração de executivos, que, diferentemente do estudo original, aparece como um fator em separado na composição dos grupos de respostas e apresenta sinalização oposta à esperada, indicando menor propensão de delação nos respondentes que apresentam uma crença maior na necessidade de divulgação da remuneração dos diretores. Este fato é consistente com o momento atual do cenário brasileiro, onde esta questão emerge nos debates corporativos.

Pode-se apontar como uma limitação deste estudo o fato de não terem sido consideradas na situação de decisão a influência das restrições e dos canais de comunicação. Ao demonstrar a existência de uma possível relação entre a percepção contábil do empregado e sua propensão a delatar, e adicionalmente ao seu tempo de atuação profissional e idade, este estudo pode auxiliar no planejamento estratégico de ações de prevenção a fraude. Esse planejamento não pode perder de vista, além da criação de canais específicos de comunicação interna para denúncia de fraudes, a atuação preponderante na conscientização interna quanto às questões contábeis e seus impactos para a organização, demonstrando a necessidade da divulgação social da importância e impacto da contabilidade na busca pela redução dos casos de fraude contábil nas organizações e minimização de seus danos.

\section{REFERÊNCIAS}

AJZEN, Icek.; FISHBEIN, Martin. Understanding attitudes and prediting social behavior. Nova Jersey: Prentice Hall. 1980.

AJZEN, Icek. ;MADDEN, Thomas J. Prediction of goal-directed behavior: Attitudes, intentions, and perceived behavioral control. Journal of Experimental Social Psychology, v. 22, n. 5, p. 453-474. 1986. DOI 10.1016/0022-1031(86)90045-4

\section{ASSOCIATION OF CERTIFIED FRAUD EXAMINERS. Report to the nations on occupation fraud and abuse. Disponível em: < http://www.acfe.com/rttn.aspx>, 2012.}

AVAKIAN, Stephanos; ROBERTS, Joanne. Whistleblowers in organisations: prophets at work? Journal of Business Ethics. Edição On line. Disponível em: $<$ http://www.springerlink.com/content/p7122844565u9025/>, 2011. DOI 10.1007/s10551011-1148-7

CHIU, Randy K. Ethical judgment and whistleblowing intention: Examining the moderating role of locus of control. Journal of Business Ethics, v. 43, p. 65-74. 2003. DOI 10.1023/A:1022911215204

CLIKEMAN, Paul M.;HENNING, Steven L. The socialization of undergraduate accounting students. Issues in Accounting Education, v. 15, n. 1, p. 1-17. 2000. DOI 10.2308/iace.2000.15.1.1

DAMATTA, Roberto. O que faz o brasil, Brasil? Rio de Janeiro, Rocco, 1986.

ELIAS, Rafik. Auditing students' professional commitment and anticipatory socialization and their relationship to whistleblowing. Managerial Auditing Journal, v. 23, n.3, p. 283-294. 2008. DOI 10.1108/02686900810857721 
FRAUDES CONTÁBEIS E WHISTLEBLOWING: UMA PESQUISA EMPÍRICA SOBRE A INFLUÊNCIA DA PERCEPÇÃO CONTÁBIL DO DELATANTE

FENG, Mei; GE, Weili; LUO, Shuqing ;SHEVLIN, Terry.Why do CFOs become involved in material accounting manipulations? Journal of Accounting and Economics, v. 51, p. 21-36. 2011. DOI 10.2139/ssrn.1260368

DODD FRANK ACT. Disponível em:

<http://www.cftc.gov/LawRegulation/DoddFrankAct/index.htm>. 2010.

GAMBAL, Vincent Paul. Public information campaigns: an application of the Theory of Reasoned Action. University of Delaware, Dissertação de mestrado (Artes em comunicação). 1990.

HAIR, Joseph. F.; BLACK, William C.; BABIN, Barry J.; ANDERSON, Rolph E.;TATHAM, Ronald L. Análise multivariada de dados. 6 ed. Bookman: Porto Alegre, 2009.

HOGAN, Chris E.; RAZAEE, Zabihollah; RILEY, Richard A.;VELURY, Uma. Financial statement fraud: Insights from the academic literature. Auditing: A Journal of Practice \& Theory, v. 27, n. 2, p. 231-252. 2008. DOI 10.2308/aud.2008.27.2.231

KAPLAN, Steven E. ; SCHULTZ, Joseph J. Intentions to Report Questionable Acts: An examination of the influence of anonymous reporting channel, internal audit quality and setting. Journal of Business Ethics, v. 71, p. 109-124. 2007. DOI 10.1007/s10551-006-00216

KARPOFF, Jonathan M.; LEE, D.Scott. ;MARTIN,Gerald S. The Cost to Firms of Cooking the Books. Journal of Financial and Quantitative Analysis, v. 43 , p 581-612. 2008. DOI $10.2139 /$ ssrn.652121

LACERDA, Tales Sarmento. Teorias da ação e o comportamento passado: um estudo do consumidor no comércio eletrônico. Universidade Federal de Minas Gerais (UFMG), Dissertação (Mestrado em Administração), Belo Horizonte. 2007.

LIPMAN, Frederick. D. From Enron to Lehman Brothers: Lessons for boards from recent corporate governance failures. Direct Notes - The conference board, p. 1-7. 2012.

LOEBBECKE, J.; EINING, M.,; WILLINGHAM, J. Auditors' experience with material irregularities: frequency, nature and detectability. Auditing: A Journal of Practice \& Theory, v. 9, p. 1-28. 1989.

McLAIN, David. L.; KEENAN, John. P. Risk, information and the decision about response to wrongdoing in an organization. Journal of Business Ethics, v. 19, n. 3, p. 255-271. 1999. DOI 10.1023/A:1006168301995

MENK, Karl Bryan. The impact of materiality, personal traits, and ethical position on whistle-blowing intentions. Virginia Commonwealth University, Tese (Doutorado em Filosofia em Negócios), Richmond. 2011.

MESMER-MAGNUS, Jessica R. ; VISWESVARAN, Chockalingam. Whistleblowing in organizations: An examination of correlates of whistleblowing intentions, actions, and 
Rossana Guerra de Sousa - Adriana Fernandes de Vasconcelos - Gustavo Amorim Antunes - José Dionísio Gomes da Silva

retaliation. Journal of Business Ethics, v 62, p. 277-297. 2005. DOI 10.1007/s10551-0050849-1

MICELI, Marcia. P. ;NEAR, Janet. P. The relationships among beliefs, organizational position, and whistle-blowing status: A discriminant analysis. Academy of Management Journal, v. 27, p. 687-705. 1984.

Blowing the Whistle: The Organizational and Legal Implications for Companies and Employees. New York: Lexington Books, 1992.

Relationships among value congruence, perceived victimization, and retaliation against whistle-blowers. Journal of Management, v. 20, n. 4, p. 773-794. 1994. DOI 10.1177/014920639402000405

studies. Human Relations, v. 55, n.. 4, p. 455-79. 2002. DOI

What makes whistleblowing effective? Three field $10.1177 / 0018726702055004463$

NEAR, Janet P.; MICELI, Marcia P. Organizational dissidence: the case of whistleblowing. Journal of Business Ethics,v.55, n.4, p. 1-16. 1985. DOI 10.1007/BF00382668

NITSH, Detlev; BAETZ Mark; HUGHES, Julia Christensen. Why code of conduct violations go unreported: A conceptual framework to guide intervention and future research. Journal of Business Ethics, v. 57, n. 4, p. 327-341. 2005. DOI 10.1007/s10551-004-8203-6

SABLE, Marjorie R.; SCHWARTZ, Lisa. R.; ELEANOR, Patricia J.; LISBON, Matthew. Using the Theory of Reasoned Action to explain physician intention to prescribe emergency contraception. Perspectives on Sexual and Reproductive Health , v. 38, n. 1, p. 20-27. 2006. DOI 10.1363/3802006

SARBANES-OXLEY ACT. Disponível em: < http://www.soxlaw.com/>, 2002.

WATTS, Ross L.; ZIMMERMAN, Jerold L. Positive accounting theory: a ten year perspective. The Accounting Review , v. 65, p. 131-156. 1990. 